Appelbaum, P. S. (1997) Almost a revolution: an international perspective on the law of involuntary commitment. Journal of the American Academy of Psychiatry and the Law, 25, 135-147.

Darsow-Schutte, K. I. \& Muller, P. (2001) Number of hospitalizations according to German 'PsychKG' legislation has doubled in 10 years. Psychiatrische Praxis, 28, 226-229.

Dressing, H. \& Salize, H. J. (2004) Compulsory admission of mentally ill patients in European Union member states. Social Psychiatry and Psychiatric Epidemiology, 39, 797-803.

Gostin, L. O. (2000) Human rights of persons with mental disabilities. The European Convention on Human Rights. International Journal of Law and Psychiatry, 23, 125-59.

Iversen, V. C., Berg, J. E., Smavik, R., et al (2011) Clinical differences between immigrants voluntarily and involuntarily admitted to acute psychiatric units: a 3-year prospective study. Journal of Psychiatric and Mental Health Nursing (in press).

Kallert, T. W., Glockner, M., Onchev, G., et al (2005) The EUNOMIA project on coercion in psychiatry: study design and preliminary data. World Psychiatry, 4, 168-172.

Knapp, M., McDaid, D., Mossialos, E., et al (2007) Mental Health Policy and Practice. European Observatory on Health Systems and Policies Series. Open University Press.
Riecher-Rossler, A. \& Rossler, W. (1993) Compulsory admission of psychiatric patients - an international comparison. Acta Psychiatrica Scandinavica, 87, 231-236.

Salize, H. J. \& Dressing, H. (2004) Epidemiology of involuntary placement of mentally ill people across the European Union. British Journal of Psychiatry, 184, 163-168.

Swanson, J. W., Holzer, C. E., 3rd, Ganju, V. K., et al (1990) Violence and psychiatric disorder in the community: evidence from the Epidemiologic Catchment Area surveys. Hospital and Community Psychiatry, 41, 761-770.

Tolmac, J. \& Hodes, M. (2004) Ethnic variation among adolescent psychiatric in-patients with psychotic disorders. British Journal of Psychiatry, 184, 428-431

Torrissen, T. (2007) Tvangsinnleggelser i en akuttpsykiatrisk post. [Involuntary admissions to an acute psychiatric ward.] Tidsskrift for den Norske legeforening, 127, 2086-2089.

UN Secretary-General (2003) Progress of efforts to ensure the full recognition and enjoyment of the human rights of persons with disabilities - report of the Secretary-General (A/58/181). Available at http://www. un.org/disabilities/default.asp?id=148 (accessed June 2011).

\title{
Naturalistic study of crisis referrals to an Irish community adult mental health service
}

\author{
Tunde Apantaku-Olajide ${ }^{1}$ MBBS, Bobby P. Smyth ${ }^{2}$ MRCPsych \\ and Pat Gibbons ${ }^{3}$ MRCPsych
}

\begin{abstract}
${ }^{1}$ Registrar in Addiction Psychiatry, Youth Drug and Alcohol Service (YoDA), Dublin, Ireland, email tunde.apantaku@hse.ie; ${ }^{2}$ Consultant Child and Adolescent Psychiatrist in Substance Use, HSE Addiction Services, Cherry Orchard Hospital, Dublin, Ireland; ${ }^{3}$ Consultant in General Adult Psychiatry, Naas General Hospital, Kildare, Ireland
\end{abstract}

Therser here is no agreed definition of a mental health crisis; however, a useful one is 'a situation where mental health has deteriorated to an extent that the user is likely to be at risk of harm to self or others and is in need of urgent intensive specialist support and treatment' (Minghella et $a l, 1998)$. Community-based care is the primary model of specialist mental healthcare in Ireland (Government of Ireland, 2006a). When clinically indicated, a patient with mental health crisis is referred to the community mental health team (CMHT) for an urgent assessment.

Most data available on the relationships between patients' explanatory variables, crisis referrals and urgent demands in mental healthcare are from international studies, which have highlighted the relevance of acute psychosis, marked affective symptoms, risk to self or others, and lack of social support (Abas et al, 2003; Johnson et al, 2005; Cotton et al, 2007). Although urgent referrals are for people in crisis, the crisis may be psychosocial in nature (Spurrell et al, 2003). Therefore, understanding mental health crisis and patients' explanatory variables within a sociocultural context is necessary for a more targeted referral system that offers optimal interventions and the appropriate use of services.

The study reported here explored the demographic and clinical characteristics of patients referred to an Irish CMHT and sought to identify the key differences between crisis and scheduled referrals.

\section{Method}

This was a retrospective analysis of the clinical records of all people who attended a CMHT within the 12 months 1 January-31 December 2008. This CMHT provides services to a well-defined catchment area in the North Kildare area of Ireland, a suburban and rural population of approximately 35000 (Government of Ireland, 2006b). The team receives referrals from 22 general practices, other CMHTs and a local general hospital emergency department. The team provides home-based assessments and treatment of acute mental illness, together with out-patient care, day hospital and inpatient care at the local general hospital where necessary.

A standard form is used for all referrals made to the team. This requires the referrer to indicate the perceived urgency of assessment. The completed form is faxed to the mental health centre office. In addition, the referrer is required to alert the home care team to crisis referrals using a designated mobile telephone number during office hours. Crisis referrals are reviewed by telephone with the referrer and an appointment offered depending on the degree of urgency as determined by the referrer, with same-day assessments available during weekday working hours. The waiting period for routine referrals is usually $7-14$ days.

Demographic data collected included age, gender and marital status, past psychiatric illness and source of referral. 
Clinical data were extracted from FACE Version 5 of the Core Assessment and Outcomes Package for Mental Health Services (Clifford, 1999). This scale is routinely completed at initial assessment. The recorded clinical data were dichotomised. Two independent groups of patients were generated from this sample. One group comprised crisis referrals; these were all patients for whom the referral source indicated 'urgent assessment'. The second group comprised the scheduled referrals, where the referral source suggested 'routine assessment', and it served as a control.

All data analyses were performed using PASW Statistics 18 (SPSS Inc., 2009). The demographic and clinical data of the two groups of patients were investigated for statistical differences, using the two-sided Fisher exact test. As this was an exploratory study, we opted not to employ a Bonferroni correction for multiple testing and left the $P$-value at 0.05 . To control for possible confounding factors, multivariate analysis was performed using the 'enter method' logistic regression model to identify variables independently associated with crisis referral. Variables were selected for entry into the regression equation based upon the results of the univariate analysis, with all variables that had a $P$-value less than 0.1 being entered.

\section{Results}

During the study period, 234 persons were referred to the service. Of these, 31 (13.2\%) (crisis referral, 13; scheduled referral, 18) did not attend; they were not different from the attenders on the sociodemographic characteristics and so were excluded from analysis. Of those who attended, 150 patients $(73.9 \%)$ had a complete set of FACE data; they did not differ on the sociodemographic characteristics of interest from patients with missing data.

The demographic and clinical characteristics of the two groups are presented in Table 1. The mean (s.d.) age of all attenders was 37.8 (15.3) years; the age range was 16-88. The crisis referral group comprised 100 people $(49.3 \%$ of the total sample), of mean age 36.4 (15.1) years, with an age range of 16-83.

On univariate analysis, recent suicidal behaviours, polysubstance use, and emergency department referral source were significantly associated with crisis referral (Table 1). Multivariate analysis indicated that polysubstance use was significantly predictive of crisis referral and memory problems were associated with routine referral (Table 2).

\section{Discussion}

In this study, almost half (49\%) of the referrals were crisis referrals, mostly from general practitioners (74\%) or the emergency department (21\%). Mainly two categories of patients present to emergency departments in Ireland: self-referrals and general practitioner referrals out of office hours. Their subsequent re-referrals to the CMHT for followup indicate that the level of crisis was manageable in the community (Hatfield et al, 2000). In the present study, the proportion of people with overt psychosis and immediate risk/safety concerns was considerably less than in a UK study (Johnson et al, 2005). The crisis referrals in our study were differentiated by recent suicidality, polysubstance use and referral via the emergency department. However, when the confounding effects of other variables were controlled for via logistic regression, only polysubstance use remained statistically significant. We also found evidence to suggest that patients presenting with memory difficulties were less likely to be referred as a crisis; this is understandable, given the potentially chronic nature of memory complaints (Neu et al, 2009).

Our findings may be explained by the limitation of crisis assessment to weekday working hours; most crisis presentations occur out of office hours, when the 'at risk' patient is likely to be admitted (Cotton et al, 2007). It is somewhat surprising that we did not detect greater differences in symptom profile between crisis and routine referrals. In particular, one might expect evidence of a more robust association between core psychiatric symptoms, risk behaviour (i.e. suicidality, self-harm and risk to others) and categorisation as a crisis referral.

\section{Clinical implications}

Our study raises two issues: the level of need for urgent assessments in community care; and the adequacy of weekday working hours provision for crisis assessments. More importantly, polysubstance use and suicidality were common among the crisis referrals; although the management of primary substance misuse is not within the remit of the $\mathrm{CMHT}$, if there is any psychiatric comorbidity then the care is a responsibility of the CMHT (Government of Ireland, 2006a). Therefore, we are emphasising the need to enhance the skills of CMHTs in managing addiction issues and the provision of more ready access to specialist addiction services, as this patient group seems particularly likely to present in crisis.

\section{Study limitations}

This study had several limitations that need to be taken into account when considering the implications of the findings. First, the study recruited patients from one CMHT in a predominantly suburban population and lacked clinical data on $26 \%$ of the attenders; therefore, the findings may not apply to patients in other CMHTs, geographical locations, or socioeconomic settings in Ireland. Second, this is an exploratory study employing multiple testing without advanced hypotheses and therefore runs the risk of a type 1 statistical error. While the logistic regression analysis controlled for confounding, it remains possible that some of the variables entered into the final regression equation were selected based upon chance associations. Third, the dichotomised data cannot capture important distinctions in the severity of symptoms or risk behaviours. Finally, we did not examine data on presentations to the emergency department out of hours and hospital admissions, because this was outside the scope of the present study.

\section{Research implications}

We suggest the need in future studies for more information on presentations to the emergency department out of hours and hospital admissions; this would help quantify the impact of available services and inform future service developments. Further research should also investigate the relationships between symptom severity, the level of patient care and onward referral pathways. 
Table 1 Demographic and clinical characteristics

\begin{tabular}{|c|c|c|c|c|}
\hline \multirow[t]{2}{*}{ Characteristic } & \multicolumn{3}{|c|}{ Proportions of patients (\%) } & \multirow{2}{*}{$\begin{array}{l}\text { Fisher test } \\
\text { significance } \\
\text { (2-sided) }\end{array}$} \\
\hline & $\begin{array}{l}\text { All } \\
\text { attendees }\end{array}$ & $\begin{array}{l}\text { Crisis } \\
\text { referrals }\end{array}$ & $\begin{array}{l}\text { Scheduled } \\
\text { referrals }\end{array}$ & \\
\hline \multicolumn{5}{|l|}{ Age (years) } \\
\hline $16-19$ & $17 / 203(8.4)$ & $10 / 100(10)$ & $7 / 103(6.8)$ & 0.40 \\
\hline $20-44$ & $122 / 203(60.1)$ & $62 / 100(62)$ & $60 / 103(58.3)$ & 0.41 \\
\hline $45-64$ & $53 / 203(26.1)$ & $23 / 100(23)$ & $30 / 103(29.1)$ & Ref. \\
\hline \multicolumn{2}{|l|}{ Gender } & $5 / 100(5)$ & $6 / 103(5.8)$ & 1.00 \\
\hline Male & $93 / 203(45.8)$ & $49 / 100(49)$ & $44 / 103(42.7)$ & 0.4 \\
\hline Female & $110 / 203(54.2)$ & $51 / 100(51)$ & $59 / 103(57.3)$ & Ref. \\
\hline \multicolumn{5}{|l|}{ Marital status } \\
\hline Single & 107/203 (52.7) & $54 / 100(54)$ & $53 / 103(51.5)$ & 1.00 \\
\hline Married & 77/203 (37.9) & $39 / 100(39)$ & $38 / 103$ (36.9) & Ref. \\
\hline Separated/widowed & $19 / 203(9.4)$ & $7 / 100(7)$ & $12 / 103(11.7)$ & 0.2 \\
\hline \multicolumn{5}{|l|}{ Source of referral } \\
\hline General practices & 158/203 (77.8) & $74 / 100(74)$ & $84 / 103(81.6)$ & 0.2 \\
\hline Emergency department & 28/203 (13.8) & $21 / 100(21.0)$ & $7 / 103(6.8)$ & 0.005 \\
\hline Other community mental health teams & $17 / 203(8.4)$ & $5 / 100(5.0)$ & $12 / 103(11.7)$ & Ref. \\
\hline Past psychiatric illness & $121 / 203(59.6)$ & $58 / 100(58)$ & $63 / 103(61.2)$ & 0.67 \\
\hline \multicolumn{5}{|l|}{ Primary diagnostic categories } \\
\hline F00-09 (organic, including symptomatic, mental disorders) & 4/203 (2.0) & $2 / 100(2)$ & 2/103 (1.9) & 0.99 \\
\hline $\begin{array}{l}\text { F10-19 (mental and behavioural disorders due to psychoactive } \\
\text { substance use) }\end{array}$ & $20 / 203(9.9)$ & $13 / 100(13)$ & $7 / 103(6.8)$ & 0.26 \\
\hline F20-29 (schizophrenia, schizotypal and delusional disorders) & $19 / 203(9.4)$ & $13 / 100(13)$ & $6 / 103(5.8)$ & 0.24 \\
\hline F30-39 (mood [affective] disorders) & $67 / 203(33.0)$ & $26 / 100(26)$ & 41/103 (39.8) & 1.00 \\
\hline F40-49 (neurotic, stress-related and somatoform disorders) & $50 / 203(24.6)$ & $23 / 100(23)$ & $27 / 103(26.2)$ & 1.00 \\
\hline F60-69 (disorders of adult personality and behaviours) & $33 / 203(16.3)$ & $19 / 100(19)$ & $14 / 103(13.6)$ & 0.47 \\
\hline Nil evident psychiatric disorder & $10 / 203(4.9)$ & $4 / 100(4)$ & $6 / 103(5.8)$ & Ref. \\
\hline \multicolumn{5}{|l|}{ Indicators of psychiatric morbidity } \\
\hline \multicolumn{5}{|l|}{$\begin{array}{l}\text { Psychotic features } \\
\text { Ps }\end{array}$} \\
\hline Thought disturbance & $9 / 150(6.0)$ & $5 / 77(6.5)$ & $4 / 73(5.5)$ & 1.00 \\
\hline Delusions & $7 / 150(4.7)$ & $6 / 77(7.8)$ & $1 / 73(1.4)$ & 0.12 \\
\hline Hallucinations & $4 / 150(2.7)$ & $3 / 77(3.9)$ & $1 / 73(1.4)$ & 0.62 \\
\hline \multirow{2}{*}{\multicolumn{5}{|c|}{ Affective features }} \\
\hline & & & & \\
\hline Overactivity & $12 / 150(8.0)$ & 6/77 (7.8) & $6 / 73(8.2)$ & 1.00 \\
\hline Expansive mood & $7 / 150(4.7)$ & $2 / 77(2.6)$ & $5 / 73(6.8)$ & 0.27 \\
\hline Anhedonia & $96 / 150(64.0)$ & 49/77 (63.6) & $47 / 73(64.4)$ & 1.00 \\
\hline Insomnia & $77 / 150(51.3)$ & $56 / 77(72.7)$ & $44 / 73(60.3)$ & 0.07 \\
\hline Depressed mood & $109 / 150(72.7)$ & $55 / 77$ (71.4) & $54 / 73(74.0)$ & 0.86 \\
\hline \multicolumn{5}{|l|}{ Neurotic features } \\
\hline Obsessions & $31 / 150(20.7)$ & 14/77 (18.2) & $17 / 73(23.3)$ & 0.55 \\
\hline Anxiety & $112 / 150(74.7)$ & $57 / 77(74.0)$ & $55 / 73(75.3)$ & 1.00 \\
\hline Somatisations & $27 / 150(18.0)$ & 10/77 (13.0) & $17 / 73(23.3)$ & 0.14 \\
\hline Dissociation & $4 / 150(2.7)$ & $4 / 77(5.2)$ & $0 / 73(0.0)$ & 0.12 \\
\hline \multicolumn{5}{|l|}{ Cognitive deficits } \\
\hline Memory & $47 / 150(31.3)$ & $19 / 77(24.7)$ & $28 / 73(38.4)$ & 0.08 \\
\hline Attention/concentration & $62 / 150(41.3)$ & 28/77 (36.4) & $34 / 73(46.5)$ & 0.25 \\
\hline Polysubstance use & $39 / 150(26.0)$ & 28/77 (36.4) & $11 / 73(15.1)$ & 0.005 \\
\hline \multicolumn{5}{|l|}{ Risk/safety concerns } \\
\hline Harm to others & $10 / 150(6.7)$ & $4 / 77(5.2)$ & $6 / 73(8.2)$ & 0.53 \\
\hline Aggression & $31 / 150(20.7)$ & $18 / 77(23.4)$ & 13/73 (17.8) & 0.42 \\
\hline Suicidal behaviours & $34 / 150(22.7)$ & $24 / 77(31.2)$ & $10 / 73(13.7)$ & 0.01 \\
\hline Self-harm & $15 / 150(10.0)$ & $10 / 77(13.0)$ & $5 / 73(6.8)$ & 0.28 \\
\hline Self-neglect & $30 / 150(20.0)$ & $18 / 77(23.4)$ & $12 / 73(16.4)$ & 0.31 \\
\hline Lack of a social support network & $43 / 150(28.7)$ & $20 / 77(26.0)$ & $23 / 73(31.5)$ & 0.48 \\
\hline
\end{tabular}

Ref. indicates the reference category where indicated.

Table 2 Results of multivariate analysis for crisis referrals

\begin{tabular}{|c|c|c|c|c|}
\hline \multirow[t]{2}{*}{ Variable } & \multirow{2}{*}{$\begin{array}{l}\text { Odds ratio } \\
\text { for crisis } \\
\text { referrals }\end{array}$} & \multicolumn{2}{|c|}{$\begin{array}{l}95 \% \text { confidence } \\
\text { interval }\end{array}$} & \multirow[t]{2}{*}{$P$-value } \\
\hline & & Lower & Upper & \\
\hline $\begin{array}{l}\text { Emergency department } \\
\text { referrals }\end{array}$ & 3.0 & 1.0 & 9.4 & 0.06 \\
\hline Suicidal behaviours & 2.0 & 0.8 & 4.8 & 0.14 \\
\hline Polysubstance use & 3.2 & 1.3 & 7.6 & 0.009 \\
\hline Memory difficulties & 0.4 & 0.2 & 1.0 & 0.04 \\
\hline Insomnia & 2.0 & 0.9 & 4.2 & 0.07 \\
\hline
\end{tabular}

\section{Conclusions}

Crisis referrals to this $\mathrm{CMHT}$ have similar symptom profiles to scheduled referrals; however, patients with substance use problems are more likely to present in crisis. Therefore, there is a need to enhance the CMHT's management of addiction issues and provide ready access to specialist addiction services. Finally, the study suggests that it is inappropriate to restrict crisis assessments to weekday office hours. 


\section{References}

Abas, M., Vanderpyl, J., Prou, T. L., et al (2003) Psychiatric hospitalization: reasons for admission and alternatives to admission in South Auckland, New Zealand. Australian and New Zealand Journal of Psychiatry, 37, 620-625.

Clifford, P. I. (1999) The FACE recording and measurement system: a scientific approach to person-based information. Bulletin of the Menninger Clinic, 63, 305-331.

Cotton, M. A., Johnson, S., Bindman, J., et al (2007) An investigation of factors associated with psychiatric hospital admission despite the presence of crisis resolution teams. BMC Psychiatry, 7, 52.

Government of Ireland (2006a) A Vision for Change. Report of the Expert Group on Mental Health Policy. Stationery Office.

Government of Ireland (2006b) Census Report. Central Statistics Office.

Hatfield, B., Spurrell, M. \& Perry, A. (2000) Emergency referrals to an acute psychiatric service: demographic, social and clinical characteristics and comparisons with those receiving continuing services. Journal of Mental Health, 9, 305-317.

Johnson, S., Nolan, F., Pilling, S., et al (2005) Randomised controlled trial of acute mental health care by a crisis resolution team: the North Islington Crisis Study. BMJ, 331, 599-602.

Minghella, E., Ford, R. \& Freeman, T. (1998) Open All Hours: 24-Hour Response for People with Mental Health Emergencies. Sainsbury Centre for Mental Health.

Neu, D., Minner, P., Le Bon, O., et al (2009) Significance of fatigue and insomnia complaints in the psychiatric emergency room. European Neuropsychopharmacology, 19, S243-S244.

SPSS Inc. (2009) PASW Statistics (18.0). SPSS Inc.

Spurrell, M., Hatfield, B. \& Perry, A. (2003) Characteristics of patients presenting for emergency psychiatric assessment at an English hospital. Psychiatric Services, 54, 240-245.

\section{Challenges for psychiatry in the 21st century}

\section{Dinesh Bhugra PhD FRCPsych}

Professor of Mental Health and Cultural Diversity, Health Service \& Population Research Department, Institute of Psychiatry, King's College London, UK, email Dinesh.bhugra@kcl.ac.uk

\section{$\mathrm{P}$} sychiatrists manage ambiguity in diagnosis as well as management of patients with psychiatric disorders and contain anxiety experienced by patients and their families as well as that of the teams. The changes in societies and cultures in the past few decades have produced changes in their expectations of their doctors, including psychiatrists. In some high-income countries, patients are better informed about their conditions and treatments than they were before. This availability of knowledge has led to a levelling in the relationship between patient and doctor.

In this paper I highlight some of the challenges psychiatry as a profession and psychiatrists as clinicians face in the early part of the 21 st century. These challenges can be divided into broad categories of social, biological and psychological factors. Social factors include globalisation and urbanisation as a result of increasing industrialisation in several countries across the globe. Biological factors include pharmacogenomics as a result of gene mapping and newer pharmacological agents. Psychological factors include computer-based therapies and stigma against patients and the profession itself.

\section{Globalisation, urbanisation and industrialisation}

Globalisation describes better communications and ease of movement of people, materials and products. The process of globalisation influences not only market forces but the political and social functioning of societies as well (see Gupta \& Bhugra, 2009; Bhugra \& Gupta, 2011). Countries can be broadly divided into: those which provide raw materials for production; those which manufacture goods; and those which are largely consumers. The movement of professionals has similar pathways. Countries may produce healthcare professionals at a lower cost but then lose them to countries which pay higher salaries, leading to serious brain drain.

Within low- and middle-income countries, increased industrialisation will lead to increased urbanisation as it did in high-income countries centuries ago. This process may cause fragmentation of families, a reduction in social support and an increase in demand for healthcare services. Furthermore, after internal migration, individuals may find that their aspirations in a number of areas are not met, which lowers self-esteem.

These factors in turn will cause changes in cultural beliefs, attitudes and values such as deculturation, affecting the individual's functioning. As a majority of the world's population is likely to reside in urban areas in the next three decades, clinicians need to be aware of the potential needs that these populations may have.

\section{Pharmacogenomics}

With new means of identifying pathology such as gene mapping, it is likely that, in due course, there will be specific medications tailored to individuals. Mrazek (2010, p. 3) defines psychiatric pharmacogenomics as the study of how gene variations influence the response of a patient to psychotropic medication. An understanding of the structural gene variants may allow drug side-effects to be minimised and genetic testing may allow the creation of bespoke 